\title{
ARTIGOS
}

\section{UMA LEITURA DOS RECORTES ESPACIAIS QUE COMPÕEM O IDH-M: O CASO DOS BAIRROS DAS GRAÇAS E BOA VIAGEM NO RECIFE}

\author{
Sandra Augusta Leão Barros ${ }^{1}$
}

Universidade de São Paulo

Daniel Lins Barros ${ }^{2}$

Universidade Federal Rural de Pernambuco

\section{Enviado em 13 set. 2020 | Aceito em 1 fev. 2021}

Resumo: Este artigo tem como premissa apresentar, discutir e relacionar as definições acerca dos recortes espaciais utilizados na elaboração e disseminação do Censo Demográfico brasileiro: limite de bairro, setor censitário e unidade de desenvolvimento humano. Associando essas poligonais aos dois bairros estudos de caso: Graças e Boa Viagem no Recife, aplicando e discutindo os números do IDH (Índice de Desenvolvimento Humano) e IDHM (Índice de Desenvolvimento Humano Municipal) obtidos no último censo de 2010 . Diante dos resultados obtidos, apontar algumas dificuldades percebidas e sugerir aspectos que poderão ser aperfeiçoados para a elaboração do próximo recenseamento. De forma simples, informativa e explicativa, sem no entanto, perder o caráter científico de uma pesquisa acadêmica.

Palavras-chave: recortes espaciais, Índice de Desenvolvimento Humano Municipal (IDH-M), Graças, Boa Viagem, Recife.

\section{A LECTURE ABOUT SPACE'S LIMITS WHICH INTEGRATE THE HUMAN DEVELOPMENT INDEX: THE CASE OF THE BOA VIAGEM AND GRAÇAS NEIGHBORHOODS IN RECIFE}

Abstract: This article has as premise to present, discuss and relate the definitions about the spatial clippings used in the elaboration and dissemination of the Brazilian Demographic Census: neighborhood limit, census sector and human development unit. Associating these polygonals to the two neighborhoods case studies: Graças and Boa Viagem in Recife, applying and discussing the numbers of the HDI (Human Development Index) and MHDI (Municipal Human Development Index) obtained in the last 2010 census. In view of the results obtained, point out some perceived difficulties and suggest aspects that could be improved for the preparation of the next census. In a simple, informative and explanatory way, however, losing the scientific character of academic research.

Keywords: spatial cuts, Municipal Human Development Index (HDI-M), Graças, Boa Viagem, Recife.

UNA LECTURA DE LOS RECORTES ESPACIALES QUE COMPONEN EL IDH-M: EL CASO DE LOS BARRIOS GRAÇAS Y BOA VIAGEM EN RECIFE

Resumen: Este artículo tiene como premisa presentar, discutir y relacionar las definiciones sobre los recortes espaciales utilizados en la elaboración y difusión del Censo Demográfico Brasileño: límite vecinal, sector censal y unidad de desarrollo humano. Asociar estos poligonales a los casos de estudio de dos barrios: Graças y Boa Viagem en Recife, aplicando y discutiendo los números del IDH (Índice de Desarrollo Humano) y del IDHM (Índice de Desarrollo Humano Municipal) obtenidos en el último censo de 2010. A la vista de los resultados obtenidos, señalar algunas dificultades percibidas y sugerir aspectos que pondrían mejorarse para la elaboración del próximo censo. De forma sencilla, informativa y explicativa, sin perder, no obstante, el carácter científico de la investigación académica.

Palabras Clave: cortes espaciales, İndice de Desarrollo Humano Municipal (IDH-M), Graças, Boa Viagem, Recife.

1. Arquiteta e Urbanista, Mestre e Dra. em Estruturas Ambientais Urbanas, FAU.USP (Faculdade de Arquitetura e Urbanismo, Universidade de São Paulo). Curso de Especialização em Gestão Pública - UFRPE (Universidade Federal Rural de Pernambuco). São Paulo, Brasil. ORCID: https://orcid.org/0000-0002-0481-6256. E-mail: sandleao@gmail.com

2. Administrador, Mestre e Prof. Dr. do Curso de Administração de Empresas, UFRPE. Curso de Especialização em Gestão Pública - UFRPE (Universidade Federal Rural de Pernambuco). ORCID: https://orcid.org/0000-0001-5487-369X E-mail: daniellins@yahoo.com.br 
Introdução

O Índice de Desenvolvimento Humano Municipal (IDH-M) apresenta uma radiografia dos dados municipais, como educação, renda, trabalho, entre outros, permitindo uma comparação ao longo do tempo e também com outros municípios do país e outras capitais. Para que o IDHM sirva de parâmetro para o direcionamento de políticas públicas e enfretamento de realidades, faz-se necessário que seja transparente e retrate de forma fiel o perfil de cada bairro da cidade.

No Brasil, as variações dos padrões de moradia, de população, de instrução e formação cultural, de renda e valores, arcabouços físico-geográficos são muito diferentes, então a forma de colher e tratar essas informações torna-se um desafio enorme. O que se pretende aqui é uma leitura desses dados a partir do IDHM de 2012, publicado no Atlas de Desenvolvimento Humano, entendendo, comparando e associando os dados com os recortes espaciais selecionados, em escalas mais aproximadas de lotes, quadras e bairros.

Assim, este trabalho tem como premissa uma abordagem temático-cartográfica onde se tenta espacializar os dados obtidos no Censo 2010 do IBGE (que integram o IDH-M), rebatidos nos limites dos Setores Censitários e dos bairros da Cidade do Recife, tomando-se como estudos de caso dois deles: Boa Viagem e Graças. Tem-se como objetivo uma leitura espacial dos dados do censo, visando interpretar alguns dos dados que integram o (IDH-M) nos componentes físico-espaciais e de qualidade de vida desses bairros, uma vez que ambos chegaram a um IDH-M acima de 0,95 no último censo

A Cidade do Recife tem um recorte peculiar. Seu desenho espraiado entre o mar e os morros que a espremem entre seus limites norte e sul a fazem compacta, mas ao mesmo tempo de situações e paisagens diversas, tendo seu território disputado palmo a palmo desde o começo de sua história, e as classes mais e menos favorecidas convivendo lado a lado, não menos sem conflitos. 
Figura 1 - Município do Recife na Região Metropolitana, com os bairros das Graças e Boa Viagem em destaque
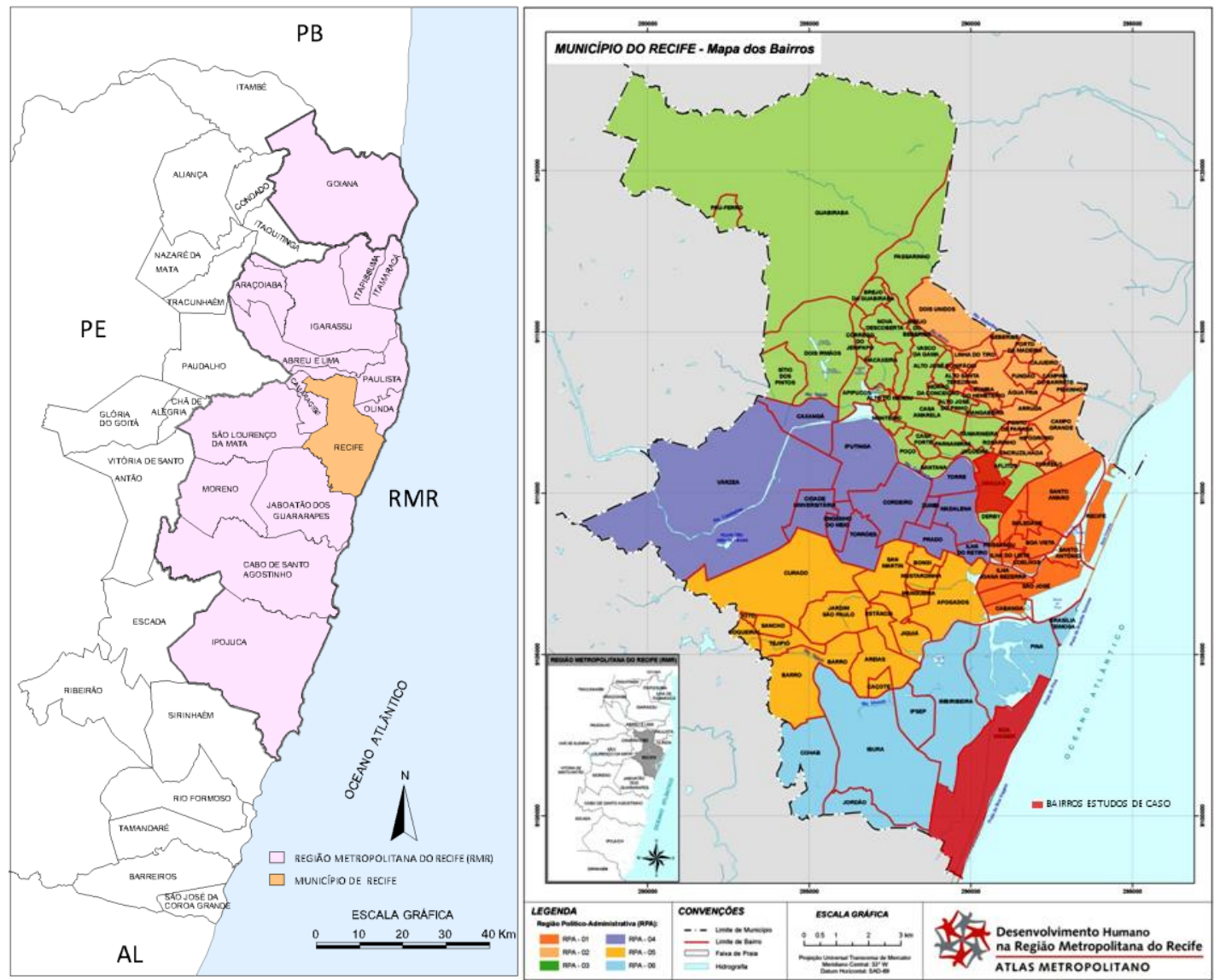

Fonte: Adaptado do Atlas de Desenvolvimento Humano da RMR, 2011.

O que se pretende é chamar atenção para os recortes espaciais que são envolvidos na elaboração do IDH e posteriormente do IDHM, considerando um bairro mais homogêneo (Graças) e outro bairro mais heterogêneo (Boa Viagem). Como objetivo geral, o trabalho tem a intenção de descrever e explicar os recortes espaciais utilizados na obtenção dos dados e na elaboração de Censo IBGE 2010, gerando a Unidade de Desenvolvimento Humano (UDH) e posteriormente o Índice de Desenvolvimento Humano Municipal e intramunicipal (IDH M), que por sua vez também se rebatem ou se traduzem em limites físico-espaciais.

Como objetivos específicos, a intenção é de apresentar, relacionar e discutir os recortes espaciais referentes aos limites de bairro, aos setores censitários, as unida des de desenvolvimento humano e as localidades apontadas com índices de desenvolvimento humano intramunicipais interiores aos bairros estudados. 
Sobrepondo, relacionando e discutindo os recortes espaciais trabalhados entre si: limites de bairro, setores censitários e unidades de desenvolvimento humano, associando-se aos IDHM geral, IDHM Educação, IDHM Renda e IDHM Longevidade, debatendo se o resultado obtido reflete realmente a realidade encontrada nos dois bairros estudados.

\section{Metodologia}

A pesquisa é descritiva, pois descreve cada um dos conceitos envolvidos, traçando toda a linha de raciocínio utilizada na elaboração de um censo demográfico e a obtenção de seus índices, entre eles o IDH e o IDHM. Pode-se, ainda, considerar como explicativa, uma vez que se tenta de forma elucidativa e educativa, explicar cada conceito trabalhado, mostrando-se o passo a passo desde a coleta das informações até o resultado propriamente dito e especializado, apontando-se as instituições responsáveis.

A pesquisa também se apresenta como documental, uma vez que se apropria dos dados do último censo nos dois bairros estudados, produzindo-se peças gráficas ilustradas ainda não realizadas dessa forma em inúmeros artigos selecionados - arquivos em autocad (ferramenta que auxilia o desenho no computador) e salvos no formato pdf nos anexos. Que permitem a observação dos setores censitários a partir das quadras e lotes, variando o padrão construtivo e de ocupação.

Para a realização desta pesquisa, foram selecionados os bairros das Graças e de Boa Viagem. Justifica-se esta escolha por terem sido freguesias muito antigas do Recife - viés histórico, hoje bairros integrantes de regiões político-administrativas diferentes; perto do mar e do rio; de tamanhos, formas e potenciais construtivos diversos; população de diferentes graus de instrução, longevidade e renda, além da oferta de equipamentos urbanos mal distribuídos; mas são bairros que, no entanto, apresentam o índice trabalhado (IDH) bem semelhante. Entender esse processo apontou para a escolha dos dois bairros.

A pesquisa foi desenvolvida em quatro etapas, apresentadas a seguir:

O primeiro passo foi selecionar e espacializar os recortes referentes aos limites de bairros e aos setores censitários nos dois bairros, sobrepondo-os as plantas cadastrais oficiais, segundo o censo IBGE 2010;

O segundo passo foi selecionar e espacializar os recortes referentes as Unidades de Desenvolvimento Humano (UDH's) nos dois bairros, sobrepondo-as as plantas cadastrais oficiais, segundo o censo IBGE 2010;

O terceiro passo foi espacializar e sobrepor numa única planta (planta cadastral de cada bairro ao fundo), os limites de bairro, gabaritos, setores censitários (unidades espaciais de coleta), unidades de desenvolvimento humano (unidades espaciais de disseminação), gerando-se um desenho com vários layers (camadas de manchas e linhas) e agregando-se todas as informações coletadas;

o quarto passo foi analisar e relacionar os índices obtidos com os recortes espaciais envolvidos. Várias conclusões e questionamentos são permitidos e visualizados.

Para concretização das etapas anteriores, fez-se necessária a utilização dos mapas do Atlas de Desenvolvimento Humano da RMR (2011), documentos oficiais disponibilizados por meio de CD ROM. Além da planta topográfica cadastral - conhecida como unibase (fornecida pela CONDEPE FIDEM, 1998, escala 1/1000) - que serviu de base para a sobreposição dos limites espaciais de bairro (fornecidos pela Prefeitura do Recife), dos setores censitários e unidades de desenvolvimento 
humano ( fornecidos pelo IBGE), somados aos gabaritos elaborados para este trabalho a partir da visualização dos bairros através do Google Maps (ferramenta online).

\section{Recortes espaciais - definições}

Os recortes espaciais do título do artigo são traduzidos nas linhas que contornam e definem espacialmente os setores censitários, os limites de bairro e as unidades de desenvolvimento humano.

\section{Limites de bairro}

Conceitualmente, bairros são subdivisões intraurbanas legalmente estabelecidas por meio de leis ordinárias das Câmaras Municipais e sancionadas pelo Prefeito. No Recife, a Lei Municipal ${ }^{\circ}$ 16.293/1997 define os limites dos 94 (noventa e quatro) bairros recifenses, assim como das 6 (seis) Regiões Político-Administrativas. Tais limites foram utilizados no Atlas de Desenvolvimento Humano e reproduzidos neste trabalho, já que são levados em conta pelo IBGE na definição dos setores censitários e unidades de desenvolvimento humano.

O bairro de Boa Viagem apresenta grande extensão territorial, aproximadamente 753 hectares, população de 122.922 habitantes e 42.272 domicílios (PERFIL DOS BAIRROS - PREFEITURA DO RECIFE, CENSO 2010). Os limites do bairro vão por toda a costa leste da orla marítima entre o Pina e a Praia de Piedade, até o município de Jaboatão ao sul, ao norte limita-se com a antiga pista do aeroclube e parque dos manguezais, a oeste limita-se com o canal do Jordão, em seguida com a pista do aeroporto internacional dos Guararapes - av. Mascarenhas de Morais e ao sul com a divisa do município de Jaboatão.

Dentro dessa faixa há desigualdades imensas, áreas de baixa renda reconhecidas como ZEIS ${ }^{3}$, áreas de baixa renda não reconhecidas oficialmente - invasões e bolsões. Por outro lado, há padrões altíssimos na faixa da orla e entorno do shopping Center Recife, que correspondem exatamente as unidades de desenvolvimento humano apresentadas a seguir.

O bairro das Graças é bem menor se comparado ao bairro de Boa Viagem, apresentando área de aproximadamente 144 hectares, população de 20.538 habitantes e 7.015 domicílios (PERFIL DOS BAIRROS - PREFEITURA DO RECIFE, CENSO 2010). Faz limite com o rio Capibaribe pelo lado oeste, bairros da Jaqueira e Rosarinho ao norte, Aflitos e Espinheiro a leste, Boa Vista e Derby ao sul/sudeste. Bairro muito antigo e consolidado na malha urbana do Recife. Uma das principais freguesias de outrora, a igreja matriz do bairro ainda é seu referencial, sendo um dos primeiros a serem servidos por linhas regulares de bonde na cidade, que o ligavam ao centro e ao terminal de Dois Irmãos. Outro elemento importante é o rio Capibaribe, que margeia toda sua face oeste, tendo o limite do bairro em seu eixo, além da quantidade de estabelecimentos de ensino. Limites que podem ser observados na figura 2 a seguir.

3. ZEIS - Zona Especial de Interesse Social, classificação pelo Plano Diretor do Recife (Lei Municipal n 17.511/2008, atualmente em revisão ). 

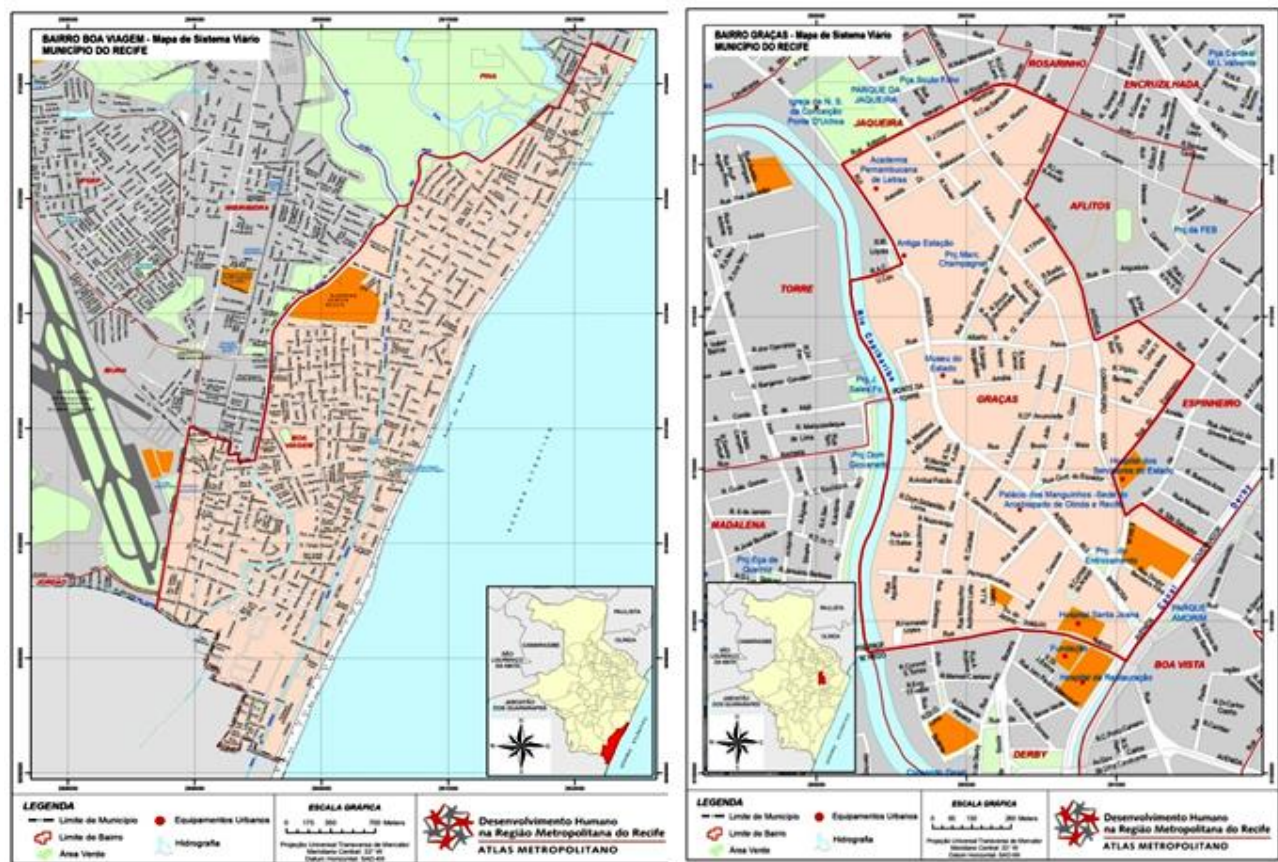

Fonte: Atlas de Desenvolvimento Humano da RMR, 2011

\section{Setores Censitários}

Há várias definições para Setor Censitário, que levam em conta: a capacidade do recenseador percorrer pequenas porções da cidade num determinado tempo, a quantidade de moradias a coletar em cada boletim, porção física da cidade em consonância com os limites da divisão políticoadministrativa do município - bairro/distrito/povoado.

Primeiramente, o setor censitário é definido como a unidade de coleta e controle cadastral, percorrida por um único recenseador, contínua e situada em área urbana ou rural de um mesmo distrito, em função do perímetro urbano (linha divisória dos espaços juridicamente distintos de um distrito, estabelecida por lei municipal). A área do setor deve respeitar os limites territoriais legalmente definidos e os estabelecidos pelo IBGE para fins estatísticos. Os limites do Setor Censitário foram definidos, preferencialmente, por pontos de referência estáveis e de fácil identificação no local (UMBELINO; BARBIERI, 2008, p.5).

Numa segunda definição, setor censitário seria a quantidade de domicílios existentes e que o recenseador é capaz de visitar no período de tempo destinado para a execução da coleta de dados, que é de aproximadamente um mês. Nas áreas urbanas, essa quantidade varia de 250 a 350 domicílios, enquanto nas áreas rurais esse valor é menor, variando entre 150 a 250 domicílios. Nas áreas rurais, além da quantidade de domicílios acrescenta-se o critério da extensão do setor censitário, sendo que um setor idealmente não deve ter mais do que 500 km² (IBGE 2013 apud BUENO; D’ANTONA, 2017, p. 18).

Numa terceira acepção, direciona para o limite de abrangência de coleta para um recenseador - define setores censitários como áreas contíguas, delimitadas para atender aos parâmetros da coleta e para controle cadastral. Situa-se em um único quadro urbano ou rural e o número de 
domicílios nele contidos e sua dimensão territorial são definidos de forma a permitir o levantamento das informações por um único recenseador. É definido em função da rota do recenseador, obedecendo a barreiras físicas e à lógica dos logradouros. Sua configuração assemelha-se às rotas dos leituristas de relógio de água, de energia elétrica, de endereçamento postal ou de coleta de lixo (normalmente quarteirões em centros urbanos, prédios muito grandes, etc). Com isso, tende a ser mais homogêneo nas áreas de maior densidade populacional e menos nas mais rarefeitas"(ATLAS DO DESENVOLVIMENTO HUMANO NO BRASIL, 2014).

Quanto maior - mais extenso for o setor censitário, significa volumes construtivos mais horizontais; quanto menores os setores censitários, significam prédios mais altos - maior verticalidade. Assim, como exemplo, o edíficio Holliday no bairro de Boa Viagem, hoje desocupado, apenas ele, já compunha um setor censitário, dada a quantidade de domicílios em seu interior. 0 bairro de Boa Viagem contabilizou 167 (cento e sessenta e sete) setores censitários no último censo.

No bairro das Graças, foram contabilizados 28 (vinte e oito setores censitários), levando-se em conta os limites utilizados no censo 2010. Nele também há setores bem verticalizados e outros nem tanto. Há muitos colégios tradicionais da cidade situados nas Graças, que ocupam muitas áreas do bairro, assim como uma legislação urbanística muito restritiva na faixa lindeira ao rio, limitando seu gabarito (Lei Municipal $n^{\circ} 16.719 / 2001^{4}$ ) Os setores censitários dos bairros estudados podem ser apreciados na figura 3 a seguir.

Figura 3 - Município do Recife na Região Metropolitana, com os bairros das Graças e Boa Viagem. A numeração dos setores não é a oficial do Censo, foram pontuados apenas para efeito de contagem e visualização

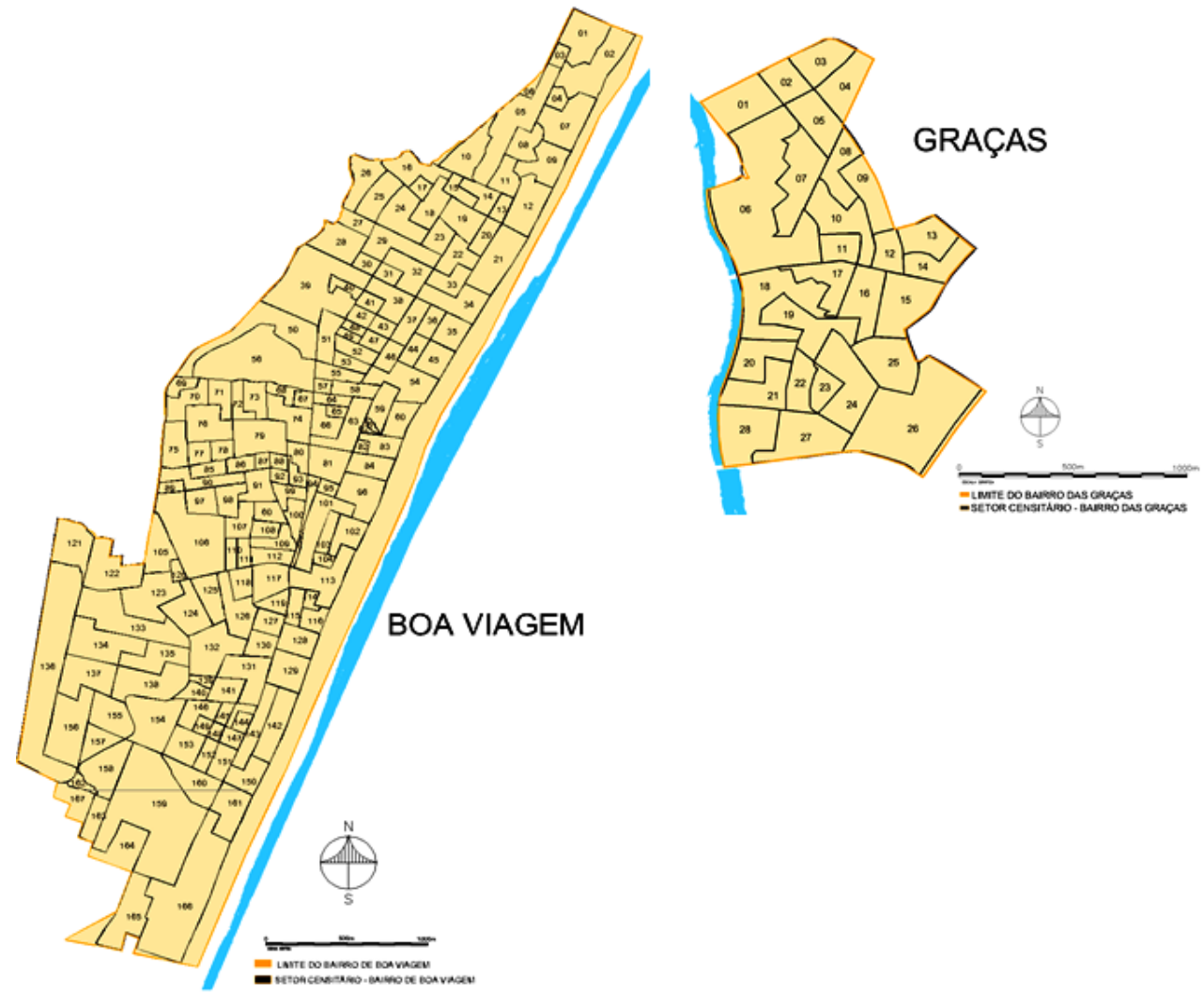

Fonte: Adaptado do Atlas de Desenvolvimento Humano da RMR, 2011.

\footnotetext{
4. Lei Municipal $n^{\circ}$ 16.719/2001 - conhecida como a Lei dos 12 Bairros, a qual estabelece uma Área de Reestruturação Urbana estendendo-se por doze bairros da margem esquerda do rio Capibaribe, indo das Graças ao Monteiro, restringindo gabaritos, remembramento de lotes, entre outros dispositivos urbanísticos.
} 


\section{Unidades de Desenvolvimento Humano (UDH)}

As Unidades de Desenvolvimento Humano (UDH's) são definidas após a coleta das informações do Censo através dos setores censitários. São tidas como agregações de setores censitários, visando uma homogeneização de áreas quanto as condições socioeconômicas, levandose em conta áreas de ponderação ${ }^{5}$. São tidas também como unidades de disseminação dos resultados do Censo, como espacialização dos dados coletados.

Para a elaboração do Atlas de Desenvolvimento Humano no Brasil, as UDHs estão voltadas para a análise espacial das Regiões Metropolitanas (RM) por meio de recortes espaciais de maior homogeneidade socioeconômica, com o objetivo de retratar as desigualdades intrametropolitanas de forma mais contundente.

Foi percebido que cada lugar tinha sua morfologia e sua história de ocupação do espaço urbano de forma diferenciada. Assim, para além das possibilidades associadas à análise das variáveis disponíveis para todos os setores censitários (que poderia ser contemplada por algum modelo econométrico), diversas situações que alteram os dados dos setores censitários (tal como a existência de um único condomínio vertical que altera a média dos dados de um setor censitário) e características da ocupação urbana (tais como idade e perfil dos assentamentos), podem não ser captadas, por exemplo, pela variável renda, e podem interferir nos indicadores sociodemográficos das UDHs. Isto fez com que fosse necessário construir a proposta das UDHs em cada RM de modo 'customizado', atentando-se para as especificidades de cada espaço metropolitano considerado.

Houve um cuidado para que essas novas UDH's fossem reconhecidas por denominações já utilizadas pela população. Na medida do possivel, tais unidades se constituiriam em agregações de setores censitários que apresentariam áreas contíguas, visando facilitar sua nomenclatura e reconhecimento. Na segunda etapa, visando a extração dos dados, os recortes definidos na primeira etapa foram ajustados para atender aos seus critérios do IBGE de um mínimo de 400 domicílios particulares permanentes amostrados por recorte. Assim, as UDHs geradas na primeira etapa, quando não atendiam a esse critério, foram agregadas a outras UDHs que apresentavam as mesmas características em termos socioeconômicos e de perfis de ocupação urbana. A agregação era realizada até que fosse alcançado para o novo recorte o mínimo dos 400 domicílios particulares permanentes amostrados. Ao final, é como se fossem geradas novas áreas de ponderação com maior homogeneidade socioeconômica, mas sem contiguidade espacial (ATLAS DO DESENVOLVIMENTO HUMANO NO BRASIL, 2014).

No bairro de Boa Viagem são apresentadas 4(quatro) Unidades de Desenvolvimento Humano (UDH's): a UDH 48 - referente a orla marítima e faixa anterior a esta (IDHM 0,964 - ano 2000); a UDH 49 - referente ao entorno do Shopping Center Recife (IDHM 0,935 - ano 2000); a UDH 47 - referente ao bairro de Setubal e proximidades (IDHM 0,927 - ano 2000); e a UDH 52 - referente as áreas de baixa renda, oficiais ou não (IDHM 0,757 - ano 2000) (ATLAS DO DESENVOLVIMENTO HUMANO NO BRASIL, 2005).

5. A área de ponderação, por seu turno, é uma unidade geográfica formada por um das Unidades de Desenvolvimento Humano (UDH). Segundo o Atlas do Desenvolvimento Humano no Brasil, 2012, corresponde a um agrupamento de setores censitários contíguos, para a aplicação dos procedimentos de calibração das estimativas obtidas com a amostra, com as informações conhecidas para a população como um todo. 
No bairro de Boa Viagem, todas as Unidades de Desenvolvimento Humano indicadas como sendo UDH 52 - correspondem as áreas de baixa renda do bairro, conhecidas como comunidades Entra Apulso, Coronel Fabriciano, Borborema entre outros bolsões de baixa renda (como ilustra a tabela 01 adiante); embora não estejam interligadas fisicamente, recebem a mesma classificação. As Unidades de Desenvolvimento Humano dos bairros das Graças e Boa Viagem podem ser apreciados na figura 4 a seguir.

\section{Figura 4 - Croquis das Unidades de Desenvolvimento Humano nos bairros das Graças e Boa Viagem}

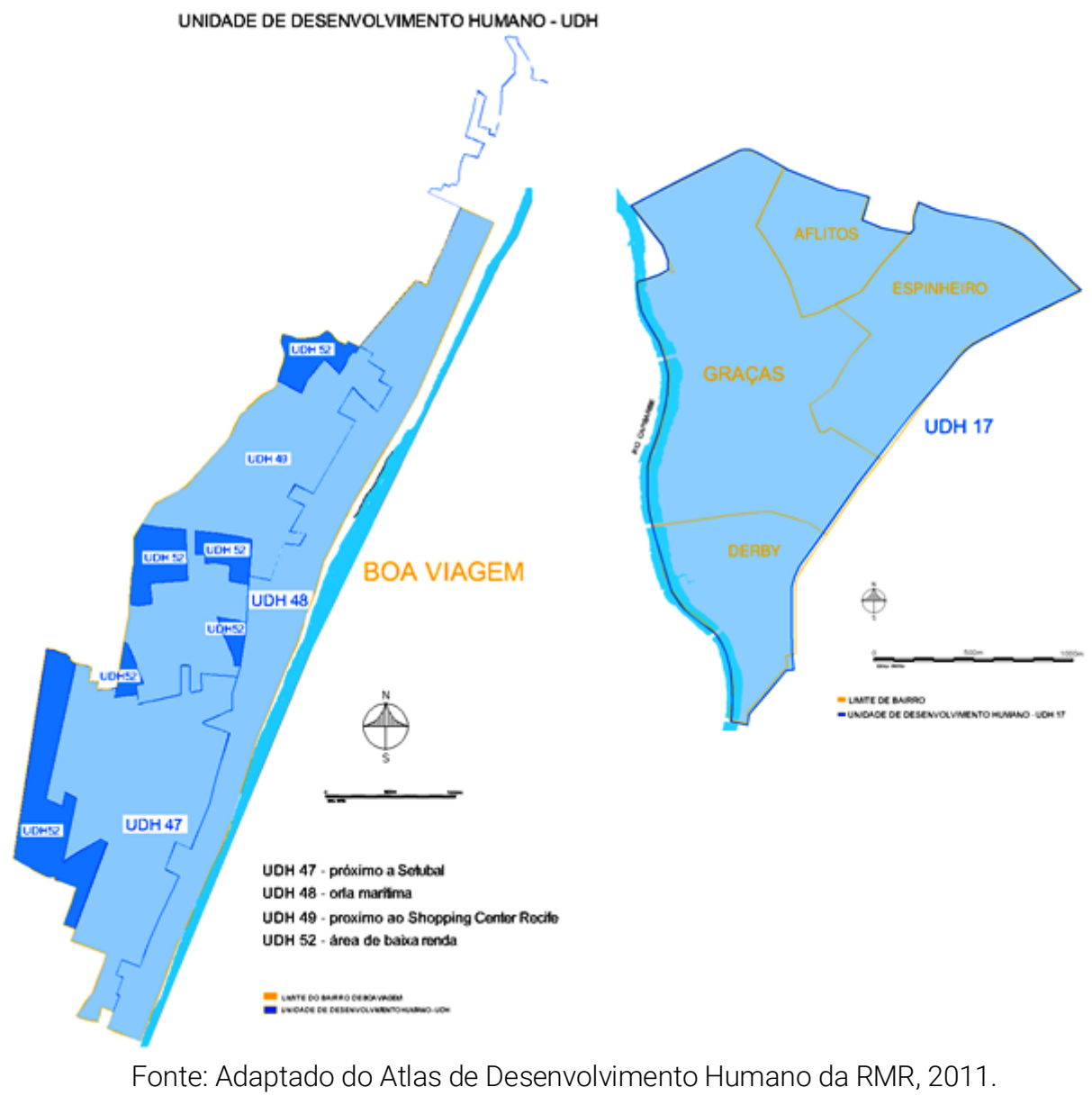

Já o bairro das Graças integra uma única Unidade de Desenvolvimento Humano (UDH 17) (IDHM 0,935 - ano 2000), em conjunto com os bairros dos Aflitos, Espinheiro e Derby. Em seguida forma trechos de duas IDHM's - Graças /Aflitos e Espinheiro (ATLAS DE DESENVOLVIMENTO HUMANO, 2005).

\section{O Índice de Desenvolvimento Humano Municipal (IDHM) e os limites de bairro e intrabairro}

O Índice de Desenvolvimento Humano (IDH) foi criado por cientistas indianos como alternativa para se medir as riquezas, qualidade de vida e expectativas de desenvolvimento para os países, principalmente aqueles do chamado terceiro mundo ou 'em desenvolvimento', em que as desigualdades e espacialidades são muito diversas e complexas, em complemento a medição do Produto Interno Bruto (PIB), que não leva em conta sua distribuição, nem características e modos de vida local que influem na qualidade e na expectativa de vida de populações residentes nesses lugares. 
Conceitualmente, desenvolvimento humano é o processo de ampliação das liberdades das pessoas, com relação às suas capacidades e às oportunidades a seu dispor, para que elas possam escolher a vida que desejam ter.

A definição e a medição do conceito de Desenvolvimento Humano transformado em Índice de Desenvolvimento Humano (IDH), foram apresentados pela primeira vez em 1990, no Relatório de Desenvolvimento Humano do Programa das Nações Unidas para o Desenvolvimento (PNUD). O IDH foi idealizado pelos economistas Mahbub ul Haq e Amartya Sen, reunindo três dos requisitos mais importantes para a expansão das liberdades das pessoas: a oportunidade de se levar uma vida longa e saudável - saúde -, de ter acesso ao conhecimento - educação -, e de poder desfrutar de um padrão de vida digno - renda. Logo obteve grande repercussão mundial devido à sua simplicidade, fácil compreensão e pela forma mais holística e abrangente de mensurar o desenvolvimento. Transformando em um único número a complexidade de três importantes dimensões, o IDH tornouse uma forma de compreensão e fomento da discussão e reflexão ampla sobre o significado do desenvolvimento humano para a sociedade (ATLAS DE DESENVOLVIMENTO HUMANO NO BRASIL, 2014).

Na sua formulação clássica, o IDH é composto por três indicadores, que representam a oportunidade de uma sociedade de ter vidas longas e saudáveis, de ter acesso a conhecimento e de ter comando sobre os recursos de forma a garantir um padrão de vida digno. Por meio das duas primeiras dimensões, pretende-se avaliar a realização do bem-estar mediante a adoção de um estilo de vida resultante de escolhas livres e informadas, a partir das habilidades e conhecimentos acumulados. Já o comando sobre recursos indica se esse processo se deu livre de privações das necessidades básicas, como as de água, alimento e moradia.

Já o Índice de Desenvolvimento Humano Municipal (IDH-M), na verdade, é uma adaptação do IDH Global para cada município brasileiro, e ainda para áreas internas a estes municípios, levando-se em conta suas peculiaridades.

Em 2012, as Nações Unidas no Brasil, junto ao Ipea e a Fundação João Pinheiro foram responsáveis pela adaptação da metodologia do IDH Global para calcular o IDH Municipal (IDHM) dos 5.565 municípios brasileiros. Foram coletadas informações dos três últimos Censos Demográficos do IBGE - 1991, 2000 e 2010 - em consoante com a malha municipal existente em 2010. Posteriormente ao cálculo do IDHM dos municípios brasileiros, as três instituições calcularam o IDHM a nível intramunicipal das regiões metropolitanas do país - desta vez, para as Unidades de Desenvolvimento Humano (UDH). Como conceito, o IDHM brasileiro leva em conta as mesmas três dimensões do IDH Global - longevidade, educação e renda -, mas tenta adequar a metodologia global ao contexto brasileiro e à disponibilidade de indicadores nacionais, eis o desafio. Embora meçam os mesmos fenômenos, os indicadores levados em conta no IDHM são mais adequados para avaliar o desenvolvimento dos municípios e regiões metropolitanas brasileiras (ATLAS DE DESENVOLVIMENTO HUMANO NAS REGIÕES METROPOLITANAS BRASILEIRAS, 2014).

\section{Como se calcula o IDH-M}

Para o cálculo do Índice de Desenvolvimento Humano Municipal são levadas em conta três dimensões: longevidade (expectativa de vida longa e saudável); educação (acesso ao conhecimento) e renda (padrão de vida). Para cada dimensão há critérios e médias que, ao final, é calculada a média geométrica (raiz cúbica) da multiplicação dos três IDHM’'s. 
Figura 5 - As três dimensões do IDH e como se calcula o Índice de Desenvolvimento Humano (IDH).

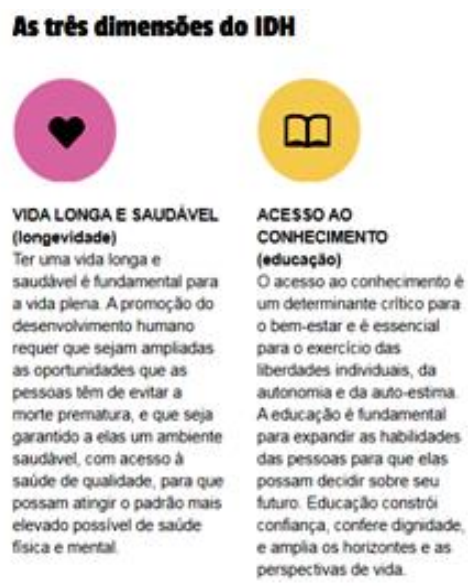

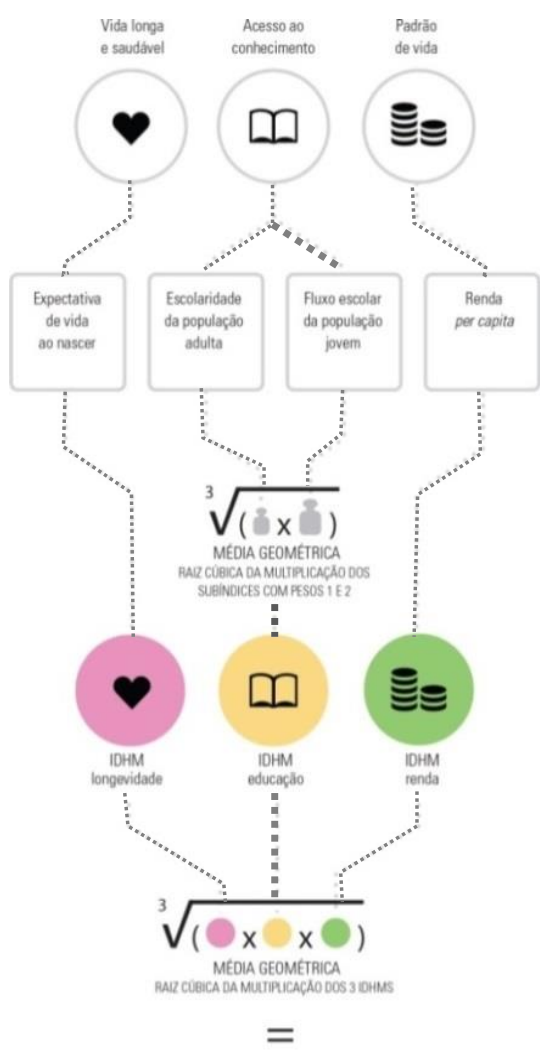

IDHM

Fonte: Atlas do Desenvolvimento Humano das Regiões Metropolitanas, 2014.

\section{Como se lê o IDH-M}

O IDHM é um número que varia entre 0 e 1. Quanto mais próximo de 1, maior o desenvolvimento humano de uma unidade federativa, município, região metropolitana ou UDH. A partir de 2010, os parâmetros de classificação passam a ser considerados os observados na figura 03. São eles: IDH: 0,800 - 1,000 (muito alto); IDH: 0,700 - 0,799 (alto); IDH: 0,600 - 0,699 (médio); IDH: 0,500 - 0,599 (baixo); IDH: 0,000 - 0,499 (muito baixo).

\section{Figura 6 - Como é lido o Índice de Desenvolvimento Humano}

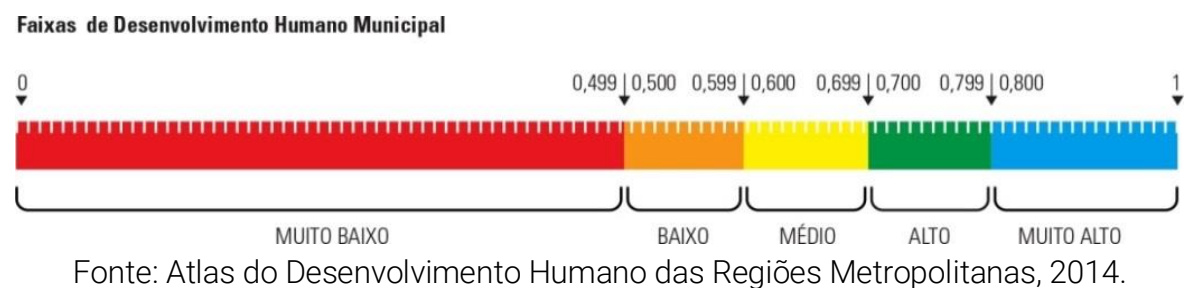


São apresentados e especializados os IDH-M's intraurbanos dos bairros de Boa Vigem e Graças, indicando-se espacialmente seus resultados, descritos na Tabela 1.

Tabela 1 - IDHM intramunicipal. Bairros das Graças, Espinheiro, Aflitos, Derby e Boa Viagem. Composição dos IDHM's Educação, Longevidade e Renda

\begin{tabular}{|c|c|c|c|c|}
\hline BAIRROS & IDHM Educação & IDHM Longevidade & IDHM Renda & $\begin{array}{c}\text { Média IDH Intra } \\
\text { Municipal }\end{array}$ \\
\hline $\begin{array}{c}\text { BOA VIAGEM - } \\
\text { ZEIS Entra Apulso } \\
\text { (Beira Rio) }\end{array}$ & 0,763 & 0,852 & 0,721 & \\
\hline $\begin{array}{l}\text { BOA VIAGEM - } \\
\text { Canal Rio Jordão/ } \\
\text { Rua Barão de Tefé }\end{array}$ & 0,824 & 0,900 & 0,805 & \\
\hline $\begin{array}{l}\text { BOA VIAGEM - } \\
\text { Edifício Holiday }\end{array}$ & 0,689 & 0,835 & 0,693 & \\
\hline $\begin{array}{l}\text { BOA VIAGEM - } \\
\text { ZEIS Entra Apulso/ } \\
\text { ZEIS Coronel } \\
\text { Fabriciano }\end{array}$ & 0,552 & 0,776 & 0,623 & \\
\hline $\begin{array}{l}\text { BOA VIAGEM - } \\
\text { Pina/ Orla }\end{array}$ & 0,903 & 0,951 & 1,000 & 0,951 \\
\hline $\begin{array}{c}\text { BOA VIAGEM - } \\
\text { Rua Bruno Veloso/ } \\
\text { Rua Barão de } \\
\text { Souza Leão/ ZEIS } \\
\text { Entra Apulso }\end{array}$ & 0,897 & 0,923 & 0,913 & \\
\hline $\begin{array}{c}\text { BOA VIAGEM - } \\
\text { Rua Vinte de } \\
\text { Janeiro/ Rua João } \\
\text { Cardoso Ayres }\end{array}$ & 0,819 & 0,902 & 0,805 & \\
\hline $\begin{array}{l}\text { BOA VIAGEM - } \\
\text { Setúbal }\end{array}$ & 0,637 & 0,920 & 0,922 & \\
\hline $\begin{array}{l}\text { BOA VIAGEM - } \\
\text { Shopping Recife/ } \\
\text { Rua Artur Muniz }\end{array}$ & 0,889 & 0,934 & 0,985 & \\
\hline $\begin{array}{c}\text { BOA VIAGEM - } \\
\text { Rua da Linha: ZEIS } \\
\text { Borborema }\end{array}$ & 0,632 & 0,797 & 0,652 & \\
\hline $\begin{array}{l}\text { BOA VIAGEM - } \\
\text { ZEIS Borborema }\end{array}$ & 0,689 & 0,835 & 0,693 & \\
\hline $\begin{array}{c}\text { BOA VIAGEM - } \\
\text { ZEIS Entra Apulso }\end{array}$ & 0,552 & 0,776 & 0,623 & \\
\hline $\begin{array}{l}\text { BOA VIAGEM - } \\
\text { ZEIS Ilha do } \\
\text { Destino }\end{array}$ & 0,660 & 0,790 & 0,645 & \\
\hline DERBY & 0,915 & 0,920 & 0,922 & \\
\hline ESPINHEIRO & 0,939 & 0,938 & 0,989 & 0,955 \\
\hline $\begin{array}{c}\text { ESPINHEIRO - } \\
\text { ZEIS Campo do } \\
\text { Vila }\end{array}$ & 0,742 & 0,816 & 0,719 & \\
\hline GRAÇAS/ AFLITOS & 0,915 & 0,944 & 1,000 & 0,952 \\
\hline
\end{tabular}

Fonte: Atlas do Desenvolvimento Humano das Regiões Metropolitanas, 2014

Numa leitura mais detalhada, a seguir são apresentadas as sobreposições dos limites de bairro, setores censitários, unidades de desenvolvimento humano e gabaritos, em cada bairro, de forma ilustrativa, para que contribuam com o entendimento das unidades de coleta e as unidades de disseminação das informações do censo, levando-se em conta o gabarito, o desenho das quadras, das ruas, dos limites dos bairros, que podem ser observados recortes nas figuras 7 e 8 a seguir. 
Figura 7 - Recortes de setores censitários do bairro de Boa Viagem. Elaborado pela autora, baseado no censo IBGE 2010 , e planta topográfica cadastral do Recife, ano 1998, escala 1/1000

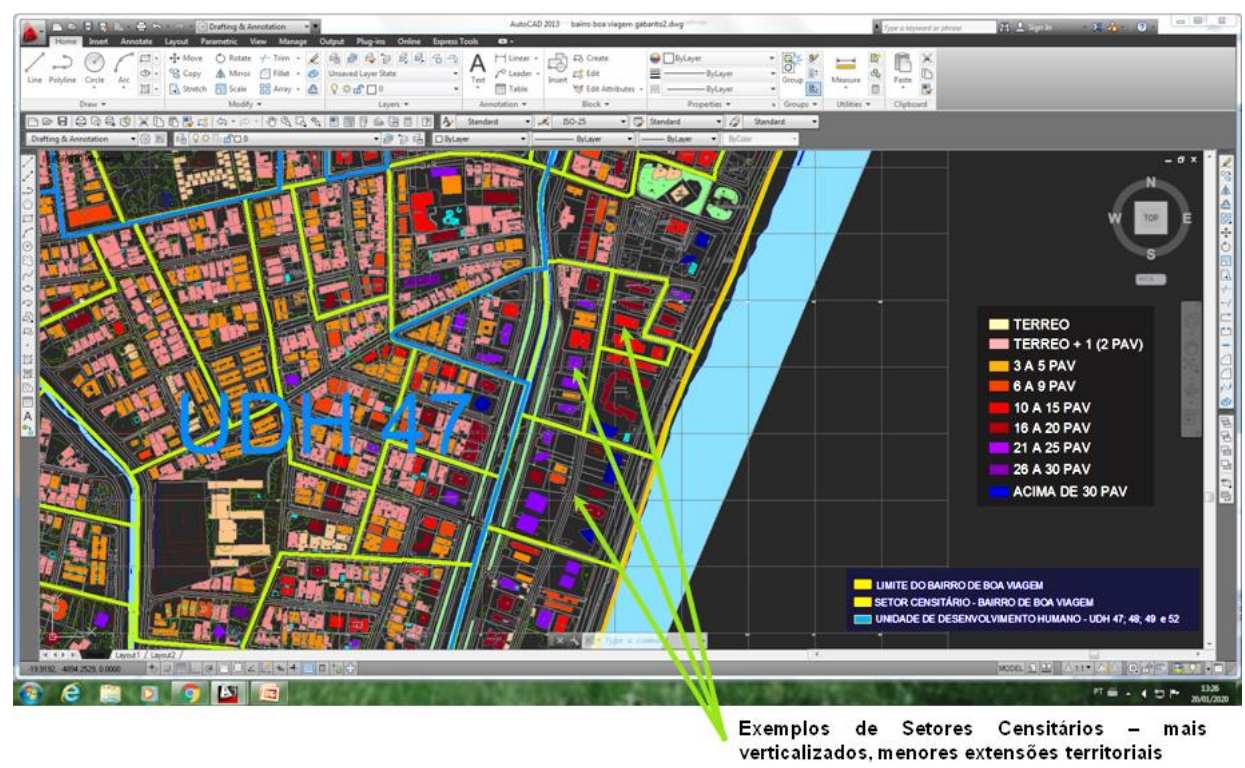

Fonte: . Intervalos de gabaritos elaborados pelos autores.

Alguns exemplos de setores censitários associados a seus gabaritos no bairro de Boa Viagem acima, onde se percebe setores menores e mais verticalizados na orla marítima. Alguns exemplos de setores censitários associados a seus gabaritos no bairro das Graças abaixo, onde se percebe setores maiores e de gabaritos mais baixos em alguns trechos.

Figura 8 - Recortes de setores censitários do bairro das Graças. Elaborado pela autora, baseado no censo IBGE 2010, e planta topográfica cadastral do Recife, ano 1998, escala 1/1000.

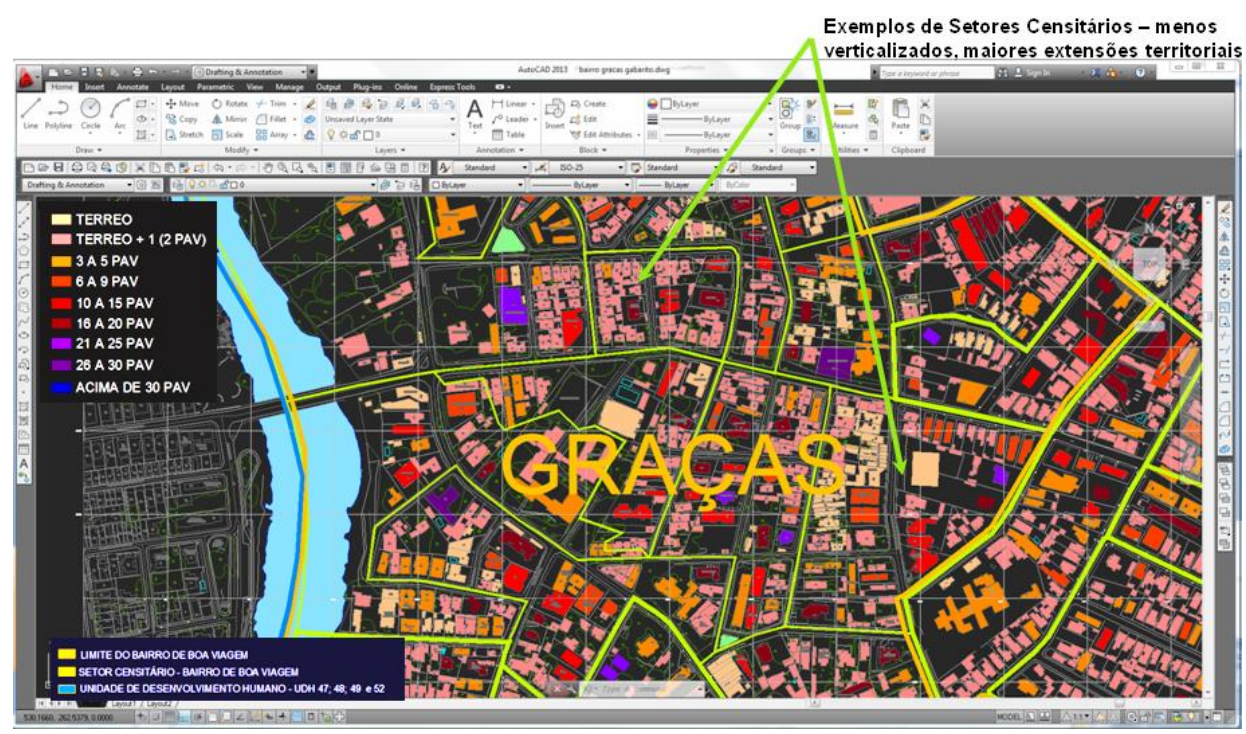




\section{Discussão}

\section{Os números do IDH e IDHM nos bairros de Boa Viagem e Graças}

O bairro de Boa Viagem apresenta uma extensão territorial bem maior que o bairro das Graças, mais populoso e com uma quantidade de setores censitários também maior. Por ser mais heterogêneo e apresentar várias áreas de baixa renda em seu interior, deu lugar a quatro tipos de UDH's (unidades de desenvolvimento humano). Enquanto que as Graças se junta com o Derby, Espinheiro, Aflitos, para formar uma única UDH. O que significa uma área de homogeneidade muito maior.

Analisando o IDH-M, o bairro das Graças apresenta os três IDH-M: Educação, Longevidade e Renda bem aproximados: 0,915; 0,944; 1,000 respectivamente. Já o bairro de Boa Viagem apresenta o IDH-M Educação e Renda bem discrepantes nas áreas de baixa renda: IDH-M Educação de 0,552 nas ZEIS Entra Apulso e Coronel Fabriciano, enquanto 0,903 na Orla/Pina; IDHM Renda de 0,623 na Entra Apulso/Coronel Fabriciano e 0,645 na Ilha do Destino, enquanto que 0,922 em Setúbal (ATLAS DE DESENVOLVIMENTO HUMANO NO BRASIL, 2014).

No caso do município do Recife, o Atlas de Desenvolvimento Humano parte dos seus 94 bairros, 6 regiões político-administrativas, 18 microrregiões e 61 ZEIS (Zonas Especiais de Interesse Social) existentes, chegando-se a uma nova subdivisão: as Unidades de Desenvolvimento Humano (UDHs) - unidades básicas adotadas no Atlas para caracterizar as áreas da cidade e melhor identificar as desigualdades sociais intraurbanas. Foram definidas 62 UDHs, que ora agregam bairros, ora os subdividem de acordo com características socioeconômicas semelhantes de seus moradores.

As UDHs foram usadas para cálculo do IDH-M, bem como as áreas agregadas mais amplas. No topo do ranking aparecem as áreas mais ricas da capital pernambucana: a orla de Boa Viagem/Pina (índice 0,964), o agregado dos bairros residenciais de Graças/Aflitos/Derby/Espinheiro (0,953), a área contígua ao Shopping Recife em Boa Viagem (0,935), por exemplo. Das 62 UDHs do Recife, nada menos do que 20 estão na faixa considerada de IDH alto, ou seja, acima ou igual a 0,8.

\section{Dificuldades, necessidades e sugestões de melhorias}

Além da visão dos números em si, alguns pontos a serem discutidos e observados visando uma melhor cobertura dos dados e retratos mais fiéis da realidade urbana:

\section{Dificuldades nas unidades de coleta - nos setores censitários}

Os setores censitários são recortes espaciais de quadras delimitadas por vias, que levam em conta a quantidade de domicílios a serem coletadas as informações para o Censo - algo em torno de 200-250 domicílios em áreas urbana; e os limites oficiais dos bairros - delimitação político administrativa municipal.

Dado que é obtido a partir do gabarito das edificações por quadra. E que provavelmente, a cada 10 anos - intervalo do censo, em áreas mais dinâmicas da cidade, irá se modificar a depender da verticalização. O que significa mudanças na delimitação dos setores censitários de um censo para o outro; dificultando a comparação, e mesmo a consideração das mesmas áreas de ponderação e 
consequentemente UDH. Causando variação na forma e extensão, necessitando de compatibilização entre as unidades antigas e as novas.

\section{Problemas na escala de abordagem e unidades de disseminação dos resultados}

As unidades de disseminação dos censos são compostas por unidades operacionais (setores censitários), unidades estatísticas (áreas de ponderação), unidades especiais (aglomerados subnormais e áreas protegidas) e unidades político-administrativas (bairros, subdistritos, distritos, municípios, unidades da federação e país). As alterações no agrupamento das unidades gerarão os resultados, alterando a unidade de desenvolvimento humano, IDH-M e áreas de ponderação. As unidades de coleta continuam com a mesma quantidade de domicílios, porém a alteração acontece na forma com que as unidades são agrupadas, gerando arranjos espaciais diferentes e variâncias dos dados também diferentes ${ }^{6}$ (BUENO; D`ANTONA, 2017, p. 22).

\section{Necessidade de base cartográfica atualizada}

Torna-se imprescindível a realização do Censo acompanhado ou apoiado em uma base cartográfica mais atualizada possível. As plantas que foram utilizadas no último censo - as unibases: plantas topográficas cadastrais - variam as escalas e os anos de sua elaboração pelo país, mas a maioria são dos anos 1990, sem muitas atualizações.

O Departamento de Cartografia do próprio IBGE vem trabalhando junto com os órgãos estaduais e municipais de cartografia, num auxílio e compartilhamento de dados mútuos, com usos de imagens de satélites e tecnologia avançada 3D, o que já ajuda muito no processo. A cidade não é estática: modificações, demolições e novos projetos aprovados ajudam a mudar a cara completamente de algumas áreas.

\section{Necessidade de abordagem do entorno imediato}

Pode-se dizer que há um consenso e uma visão aceita pela maioria de que não só a qualidade da moradia em si influi na qualidade do local, no bem estar e longevidade dos moradores. Igualmente influi o espaço urbano externo a moradia. Sendo assim, o Censo 2021 pretende começar a coletar dados de infraestrutura urbana de alguns municípios brasileiros numa pequena amostragem, para uma primeira testagem e ajustes. É um avanço grande em relação ao último censo 2010.

No Censo 2021 será verificada a existência de calçamento nas ruas, de pontos de ônibus, de ciclovias, de arborização, além de pesquisar quesitos de acessibilidade, como a presença de piso tátil e de rampas para pessoas com deficiência. Serão levantados temas que promovem uma maior equidade de acesso na cidade, como a existência de áreas de travessias para pedestres e de trânsito compartilhado com bicicletas. Além da questão da arborização, que promove o conforto climático. Esses resultados podem se tornar indicadores de sustentabilidade. Essa operação serve como teste para a Pesquisa Territorial do Entorno Urbanístico dos Domicílios, que acontecerá em todos os municípios do país dois meses antes do início da coleta do próximo Censo.

Serão contempladas localidades com infraestrutura mais precárias, como as favelas, categorizadas pelo IBGE como aglomerados subnormais. Essas áreas foram incluídas no último Censo, mas agora serão testadas e avaliadas utilizando-se uma metodologia diferente, que permite

6. Se tal povoado, distrito ou área protegida pertence a um bairro tal, vai influenciar diretamente o IDHM intraurbano dessa vizinhança imediata. 
coletar as informações de aglomerações subnormais que não têm arruamento regular. Através de uma nuvem de pontos que vai dar a característica espacial de cada lugar (IBGE VERIFICA INFRAESTRUTURA URBANA DE 21 MUNICÍPIOS PARA TESTE DO CENSO 2020).

Pesquisas desse tipo já vem sendo utilizadas para seleção das localidades que iriam receber os imóveis do Programa Minha Casa Minha Vida no Estado de São Paulo, por exemplo. Como se ilustra a seguir na tabela 2.

Tabela 2 - Pesquisa de indicadores externos as residências para seleção das localidades que receberiam os empreendimentos do Programa Minha Casa Minha Vida no Estado de São Paulo

\begin{tabular}{|c|c|c|c|c|}
\hline Tema & $\begin{array}{l}\text { Elaborar a pergunta } \\
\text { a ser respondida }\end{array}$ & Dados & Perguntas especificas & Indicadores \\
\hline \multirow{3}{*}{$\begin{array}{l}\text { Equipamentos } \\
\text { urbanos }\end{array}$} & \multirow{3}{*}{$\begin{array}{l}\text { Os empreendimentos } \\
\text { possuem } \\
\text { infraestrutura de } \\
\text { equipamentos nas } \\
\text { proximidades? }\end{array}$} & $\begin{array}{l}\text { Educação } \\
\text { (EMEF,EMEI,EE,CEI) }\end{array}$ & $\begin{array}{l}\text { Quantas escolas estão } \\
\text { acessíveis? }\end{array}$ & $\begin{array}{l}N^{\circ} \text { de equipamentos na proximidade dos } \\
\text { empreendimentos }\end{array}$ \\
\hline & & $\begin{array}{l}\text { Saúde (AMA, UBS, } \\
\text { HOSPITAL) }\end{array}$ & $\begin{array}{l}\text { Quantos equipamentos de } \\
\text { saúde estão acessíveis? }\end{array}$ & $\begin{array}{l}\mathrm{N}^{\circ} \text { de equipamentos na proximidade dos } \\
\text { empreendimentos }\end{array}$ \\
\hline & & Parques & $\begin{array}{l}\text { Existem parques com função } \\
\text { de lazer próximo aos } \\
\text { empreendimentos? }\end{array}$ & $\begin{array}{l}N^{\circ} \text { de equipamentos na proximidade dos } \\
\text { empreendimentos }\end{array}$ \\
\hline Mobilidade & $\begin{array}{l}\text { Os habitantes } \\
\text { possuem } \\
\text { infraestrutura de } \\
\text { transporte? }\end{array}$ & Acessibilidade & $\begin{array}{l}\text { Quantos pontos de ônibus e } \\
\text { de metro estão próximos aos } \\
\text { empreendimentos? }\end{array}$ & $\begin{array}{l}\mathrm{N}^{\circ} \text { de pontos de ônibus, metrô e trem nas } \\
\text { proximidades dos empreendimentos }(500 \mathrm{~m}, 1 \mathrm{~km} \text {, } \\
1.5 \mathrm{~km})\end{array}$ \\
\hline $\begin{array}{l}\text { Cobertura } \\
\text { vegetal }\end{array}$ & $\begin{array}{l}\text { Os habitantes têm } \\
\text { acesso a áreas com } \\
\text { cobertura vegetal? }\end{array}$ & Cobertura vegetal & $\begin{array}{l}\text { Existe cobertura vegetal } \\
\text { próximo aos } \\
\text { empreendimentos? }\end{array}$ & $\begin{array}{l}\text { Cobertura vegetal por setor OD com } \\
\text { empreendimentos do MCMV }\end{array}$ \\
\hline \multirow{2}{*}{ Esgotamento } & \multirow{2}{*}{$\begin{array}{l}\text { Os habitantes têm } \\
\text { acesso ao sistema de } \\
\text { esgotamento } \\
\text { sanitário? }\end{array}$} & \multirow{2}{*}{ Coleta de esgoto } & \multirow{2}{*}{$\begin{array}{l}\text { Os empreendimentos estão } \\
\text { inseridos dentro da área de } \\
\text { cobertura da rede de coleta } \\
\text { esgoto? }\end{array}$} & $\begin{array}{l}\text { Número de empreendimentos atendidos pelo } \\
\text { sistema de esgotamento da SABESP }\end{array}$ \\
\hline & & & & $\begin{array}{l}\text { Número de empreendimentos não atendidos pelo } \\
\text { sistema de esgotamento da SABESP }\end{array}$ \\
\hline \multirow{2}{*}{ Abastecimento } & \multirow{2}{*}{$\begin{array}{l}\text { Os habitantes têm } \\
\text { acesso ao sistema de } \\
\text { abastecimento de } \\
\text { água? }\end{array}$} & \multirow{2}{*}{ Abastecimento de água } & \multirow{2}{*}{$\begin{array}{l}\text { Qual a qualidade do } \\
\text { abastecimento de água nos } \\
\text { setores que possuem } \\
\text { empreendimentos? }\end{array}$} & $\begin{array}{l}\text { Indice de Regularidade de adução (IRA) } \\
\text { Indice de Reclamação de Falta de Aggua (IRFA) }\end{array}$ \\
\hline & & & & Índice de Regularidade da Distribuição (IRD) \\
\hline \multirow{2}{*}{ Área de risco } & \multirow{2}{*}{$\begin{array}{l}\text { Existem } \\
\text { empreendimentos } \\
\text { próximos a áreas de } \\
\text { risco? }\end{array}$} & Inundação & $\begin{array}{l}\text { Quantos empreendimentos } \\
\text { estão próximos às áreas } \\
\text { sujeitas à inundação? }\end{array}$ & $\begin{array}{l}N^{\circ} \text { de empreendimentos próximos }(500 \mathrm{~m}) \text { às áreas } \\
\text { sujeitas a inundação }\end{array}$ \\
\hline & & Áreas contaminadas & $\begin{array}{l}\text { Quantos empreendimentos } \\
\text { estão próximos às áreas } \\
\text { contaminadas? }\end{array}$ & $\begin{array}{l}N^{0} \text { de empreendimentos próximos }(500 \mathrm{~m}) \text { às áreas } \\
\text { contaminadas }\end{array}$ \\
\hline
\end{tabular}

Fonte: SIQUEIRA-GAY, 2016.

\section{Considerações finais}

Uma das intenções do trabalho foi chamar atenção para o IDHM intraurbano, que muitas vezes não retrata fielmente a realidade urbana dos municípios brasileiros. Dentro de um mesmo bairro ou área da cidade pode haver comunidades de baixa renda junto das de altíssimas rendas, que acabam se beneficiando no resultado do IDHM intraurbano, mas na prática não têm acesso aos mesmos serviços, nem renda e nem longevidade. Tais áreas no bairro de Boa Viagem apresentam IDH-M acima de 0,7 , tidas como altas na escala do IDH. A realidade brasileira é complexa, e isso se traduz no espacial. O desafio é grande, em como transformar esses números num espelho real e aproveitá-los em políticas públicas para os menos favorecidos é outro passo enorme a ser dado.

É no lócus espacial, no casco urbano onde as desigualdades sócio-econômico culturais acontecem ou se planificam. A forma de colher esses dados e processá-los, chegando aos números apontados como IDH, IDH-M, é o foco deste trabalho. A cidade é desigual por essência, e desiguais serão os resultados. Entender até onde a desigualdade dos resultados é verdadeira e reflete aquele bairro ou adjacência, eis a questão. Recife não foge disso, antes ainda o enfatiza.

Outros índices já foram criados na intenção de aferir a realidade brasileira. O que mostra que o IDHM ainda não é o mais perfeito e aceito, porém é um dos mais utilizados como método gerencial de todo o território brasileiro, utilizando-se os dados dos recenseamentos. 
Mesmo o PNUD admite que o IDH não é uma medida absoluta de desenvolvimento humano, devido à complexidade do tema. Especialistas destacam que há outros fatores que determinam o grau de felicidade em um país, que não são medidos pelo indicador, como nível de democracia e liberdade de expressão. O IDH compartilha das mesmas limitações de outras medidas. Mas é importante mantê-lo simples, com o mínimo de variáveis, para garantir aceitação, entendimento e previsibilidade (O QUE É O IDH - Jornal o Globo, RJ, 21/03/2017).

O cerne da questão não é discutir a confiabilidade ou não do IDH, nem tampouco propor um outro índice de aferição da qualidade de vida, crescimento e cidadania. Mas o objetivo é discutir e chamar atenção para a delimitação dos recortes espaciais envolvidos. Tudo se passa sobre um suporte físico-territorial: demarcado por quadras, vias, edificações, vazios, invasões. De várias faces pelo país. Adotar o limite político-administrativo de bairro pode ser um bom começo, no entanto muito precisa avançar para se chegar a um limite/recorte ideal. Tanto na unidade de coleta (setor censitário) como na de disseminação (unidade de desenvolvimento humano).

Os bairros das Graças e Boa Viagem serviram para mostrar que, apesar de apresentarem diferenças intra bairro em seus IDHM Renda, Educação e Longevidade, além do tamanho, geografia, gabarito e quantidade de domicílios, na contabilização e ponderação dos resultados muito se aproximam. O que trouxe muita inquietude sobre toda essa metodologia de ação e execução do IDH. Tornando claro, por outro lado, a necessidade cada vez mais da interdisciplinaridade nos números do Censo: o entrelaçamento de dados econômicos, geográficos, de planejamento urbano, de gestão do território, de cartografia entre outros. 


\section{Referências}

ABNT NBR 6023:2018 - Informação e documentação: Referências - Elaboração. Rio de Janeiro: Associação Brasileira de Normas Técnicas, 2018. ISBN 978-85-07-07757-2.

ABRANTES, Talita (2014). Os bairros do Brasil que poderiam estar na Noruega. Disponível em: https://exame.abril.com.br/brasil/os-bairros-do-brasil-que-poderiam-estar-na-noruega/ . Acessado em 17 jan 2019.

ABREU, Marcos Vinicius Sanches; OLIVEIRA, Julio Cesar de; ANDRADE, Viviane Delfino Albuquerque; MEIRA, Anderson Donizete (2011). Proposta metodológica para o cálculo e análise espacial do IDH intraurbano de Viçosa - MG. Revista Brasileira de Estudos Populacionais . Rio de Janeiro, vol.28, n.1, pp.169-186. ISSN 0102-3098. Disponível em: http://dx.doi.org/10.1590/S010230982011000100009. Acessado em 23 jan 2019.

ATLAS do Desenvolvimento Humano nas Regiões Metropolitanas Brasileiras - Série Atlas do Desenvolvimento Humano no Brasil (2014). Rio de Janeiro: IPEA, Fundação João Pinheiro, PNUD Brasil. ISBN 978-85-88201-21-7. Disponível em: https://www.br.undp.org/content/brazil/pt/home/idh0/atlas-do-desenvolvimento-humano/atlas-dodesenvolvimento-humano-nas-regioes-metropolitanas-brasi.html. Acessado em 24 nov 2019..

ATLAS do Desenvolvimento Humano na Região Metropolitana do Recife (2011). Recife: Programa das Nações Unidas para o Desenvolvimento (PNUD), Fundação João Pinheiro, Prefeitura do Recife.CD ROM.

ATLAS do Desenvolvimento Humano no Recife (2005). Atlas Municipal. Recife: PNUD Brasil, Ministério da Integração Nacional, Prefeitura do Recife. CD ROM.

BACIUK, Erica Passos (org.) (2018). Políticas Públicas e Desenvolvimento Humano. Curitiba: CRV. ISBN 978-85-444-2888-7.

BARBOSA, Francis Regis Gonçalves Mendes (2017). Índice de Desenvolvimento Relativo, IDH-M e IFDM: em busca da operacionalização das liberdades instrumentais de Amartya Sen. Revista Ensaios FEE, Porto Alegre, v. 38, n. 2, pp. 295-328. Disponível em: https://revistas.fee.tche.br/index.php/ensaios/article/view/3631. Acessado em 29 nov 2019.

BARROS, Georgia Fernandes; OLIVEIRA, Ana Maria Hermeto Camilo de; AMARAL, Pedro Vasconcelos M. do (2016). Desenvolvimento humano e acesso a serviços: uma análise espacial para os municípios brasileiros. Minas Gerais: Centro de Desenvolvimento e Planejamento Regional/ UFMG. Disponível em: http://abep.org.br/xxencontro/files/paper/715-754.pdf. Acessado em 29 nov 2019.

BUENO, Maria do Carmo Dias; D’ANTONA, Alvaro de Oliveira (2017). A geografia do Censo no Brasil: potencialidades e limitações na execução de análises espaciais. Revista Geographia, vol. 19, n. 39, 2017, pp. 16-28. Niterói: Universidade Federal Fluminense. ISSN 15177793. Disponível em: https://www.researchgate.net/publication/317067250. Acessado em 21 set 2019.

BITOUN, Jan (2005). O que revelam os índices de desenvolvimento humano. Série Aspectos do Desenvolvimento Humano no Recife. Atlas do Desenvolvimento Humano no Recife.

CABALLERO, Barbara (2016). IDH-M: uma análise do Indice de Desenvolvimento Humano Municipal para a Cidade do Rio de Janeiro. Rio de Janeiro: Instituto Pereira Passos (IPP), Prefeitura da Cidade do Rio de Janeiro. Disponível em: http://www.rio.rj.gov.br/dlstatic/10112/6165511/4162028/analise_idhm_rio_v4_compur.pdf.

Acessado em 29 nov 2019.

Censo Demográfico 2000: características da população e dos domicílios - resultados do universo. Rio de Janeiro: IBGE, Ministério do Planejamento, Orçamento e Gestão. ISSN 01043145.

COSTA, Alisson Luiz da; SOUZA, Bruna Rodrigues; SARAIVA, Gilsilene Sampaio; PEREIRA, Pedro Augusto Miranda; OLIVEIRA, Tacio Rodrigues Batista de (2015). Análise Espacial da Evolução do IDHM do Município de Maceió. In: $3^{\circ}$ GEOALAGOAS - Simpósio sobre as Geotecnologias e Geoinformação no Estado de Alagoas. Maceió/AL. Disponível em: http://dados.al.gov.br/dataset/d2055bec-f83f49e1-a6d8-4d05db204f64/resource/ed1f750a-75ac-4473-83c7-

5ba7be5ad31d/download/analiseespacialdaevolucaodoidhmdomunicipiodemaceio.pdf. Acessado em 29 nov 2019. 
Entenda o cálculo do IDH Municipal (IDH-M) e saiba quais os indicadores usados. Disponível em: http://www.frigoletto.com.br/GeoEcon/idhmcalc.htm. Acessado em 03 jul 2019.

IDHM do Grande Recife melhora, mas região figura entre as piores do país. Disponível em: http://g1.globo.com/pernambuco/noticia/2014/11/idhm-do-grande-recife-melhora-mas-regiao-

figura-entre-piores-do-pais.html . Acesadso em 03 jul 2019.

Instituto Brasileiro de Geografia e Estatística - IBGE (2013). Metodologia do Censo Demográfico de 2010. Série Relatórios Metodológicos, v. 41. Rio de Janeiro: IBGE.

GUSMÃO, Luiz Henrique Almeida (2016). Cartografia e IDH da Região Metropolitana de Belém. Geografia e Cartografia Digital. Disponível em: http://geocartografiadigital.blogspot.com/2016/06/cartografia-e-idh-da-regiao.html. Acessado em 29 nov 2019.

Lei Municipal n 16.293, de 22/01/1997 - dispõe sobre as Regiões Político-Administrativas e bairros componentes do Município do Recife. Recife: Secretaria de Planejamento, Urbanismo e Meio Ambiente, 1997.

MARGUTI, Barbara Olveira; COSTA, Marco Aurelio; FAVARÂO, Cesar Bruno (orgs.) (2017). Territórios em números: insumos para políticas públicas a partir da análise do IDHM e do IVS de UDHs e regiões metropolitanas brasileiras. Brasília: IPEA: INCT, livro 2. ISBN 978-85-7811-297-4. Disponível em: http://www.ipea.gov.br/portal/index.php?option=com_content\&view=article\&id=30508\&ltemid=424 . Acessado em 02 jan2020.

MARTINS, Cristina Maria dos Reis; GERMANO, Liane Rose Reis Garcia Bayard das Neves; RANGEL, Rodrigo Rodrigues (2016). Metodologia das Unidades de Desenvolvimento Humano da Região Metropolitana de Porto Alegre. Revista Indicadores Econômicos, Fundação de Economia e Estatística (FEE), Porto Alegre, v. 43, n. 4, p. 91-108. Disponível em: https://revistas.fee.tche.br/index.php/indicadores/article/view/3668. Acessado em 21 set 2019.

NAJBERG, Sheila; OLIVEIRA, Paulo André de Souza de (2000). Políticas Públicas: o Indice de Desenvolvimento Humano (IDH) e variantes. BNDES, Secretaria para Assuntos Fiscais (SF). Jornal Informe SF, $\quad$ n. $19 . \quad$ Disponível em: https://www.bndes.gov.br/SiteBNDES/export/sites/default/bndes_pt/Galerias/Arquivos/conhecime nto/informesf/inf_19.pdf. Acessado em 01 de abr de 2020.

ORGANIZAÇÃO DAS NAÇÕES UNIDAS (ONU). Programa das Nações Unidas para o Desenvolvimento (PNUD) (2014). Atlas do Desenvolvimento Humano no Brasil. Disponível em: http://www.atlasbrasil.org.br/2013/. Acessado em 04 fev 2019.

O que é o IDH. Jornal o Globo(2017). Disponível em: https://oglobo.globo.com/economia/o-que-oidh18280276\#: :text=0\%20Pnud\%20admite\%20que\%20o,democracia\%20e\%20liberdade\%20de\%20 express\%C3\%A3o. Acessado em 21 jan 2020.

PAIVA, Maria das Graças; LIBANIO, José Carlos (2005). IDH-M dentro do Recife vai da África à Noruega. Disponível em: https://www.recife.pe.gov.br/pr/secplanejamento/pnud2006/doc/releases/IDHM\%20dentro\%20do\%20Recife\%20vai\%20da\%20\%C3\%81frica\%20\%C3\%A0\%20Noruega.pdf

Acessado em 10 jan 2019.

Planta Topográfica Cadastral. Unibases nº UNI 91:00; 90:05; 90:00; 99:05; 89:05; 89:55. Recife: Condepe/Fidem, 1998, escala 1/1000.

PNUD analisa o impacto do IDHM na gestão pública brasileira (2013). Fonte: PNUD Brasil, Atlas Brasil. Disponível em:

http://www.br.undp.org/content/brazil/pt/home/presscenter/articles/2014/04/24/pnud-analisa-oimpacto-do-idhm-na-gest-o-p-blica-brasileira.html. Acessado em 22 jan 2019.

PREARO, Leandro Campi; MARACCINI, Maria Clara; ROMEIRO, Maria do Carmo (2015). Fatores determinantes do Indice de Desenvolvimento Humano dos Municípios do Estado de São Paulo. Revista Brasileira de Políticas Públicas, vol. 5, n. 1, pp. 133-156. ISSN 236-1677. Disponível em: https://www.publicacoes.uniceub.br/RBPP/article/view/2960. Acessado em 23 jan 2019. 
RENAUX, Pedro (2019). IBGE verifica infraestrutura urbana de 21 municípios para teste do Censo 2020. Agência IBGE Notícias. Disponível em: https://agenciadenoticias.ibge.gov.br/agencianoticias/2012-agencia-de-noticias/noticias/23816-ibge-verifica-infraestrutura-urbana-de-21municipios-para-teste-do-censo-2020. Acessado em 27 jan 2020.

ROCHA, Camilo (2017). A origem, o poder e as dificuldades das cidades no Brasil - pensamento político do século 21 destaca protagonismo dos municípios, que sentem falta de mais autonomia e dinheiro. Nexo Jornal. Disponível em: https://www.nexojornal.com.br/explicado/2017/01/01/Aorigem-o-poder-e-as-dificuldades-das-cidades-no-Brasil. Acessado em 23 jan 2019.

SIQUEIRA-GAY, Juliana (2016). Estratégias para integração de temas socioambientais no planejamento de habitação social no município de São Paulo. Disponível em: https://www.researchgate.net/publication/306356438_Estrategias_para_integracao_de_temas_soci oambientais_no_planejamento_de_habitacao_social_no_municipio_de_Sao_Paulo. Acessado em 01 abr de 2020.

UMBELINO, Glauco; BARBIERI, Alisson (2008). Metodologia para a compatibilização de setores censitários e perímetros urbanos entre os censos de 1991, 2000 e 2010. In: XVI Encontro Nacional de Estudos Populacionais. Caxambu/MG. Disponível em http://www.abep.org.br/publicacoes/index.php/anais/article/view/1872. Acessado em 29 nov 2019. 